

\title{
Tellurium-doped lanthanum manganite as catalysts for the oxygen reduction reaction
}

\author{
V. Celorrio, School of Chemistry, University of Bristol, Cantocks Close, Bristol BS8 1TS, UK \\ L.J. Morris, School of Chemistry, University of Bristol, Cantocks Close, Bristol BS8 1TS, UK; EPSRC Centre for Doctoral Training in \\ Catalysis, School of Chemistry, Cardiff University, Main Building, Park Place, Cardiff CF10 3AT, UK \\ M. Cattelan, N.A. Fox, and D.J. Fermin, School of Chemistry, University of Bristol, Cantocks Close, Bristol BS8 1TS, UK \\ Address all correspondence to: D.J. Fermin at david.fermin@bristol.ac.uk
}

\begin{abstract}
The effect of tellurium ( $\mathrm{Te}$ ) doping on the electrocatalytic activity of $\mathrm{La}_{1-\mathrm{x}} \mathrm{Te}_{\mathrm{x}} \mathrm{MnO}_{3}$ toward the oxygen reduction reaction is investigated for the first time. $\mathrm{La}_{1-x} \mathrm{Te}_{\mathrm{XMnO}} \mathrm{Mn}_{3}$ with $\mathrm{x}$-values up $23 \%$ were synthesized from a single ionic liquid-based precursor, yielding nanoparticles with mean diameter in the range of $40-68 \mathrm{~nm}$ and rhombohedral unit cell. Electrochemical studies were performed on carbon-supported particles in alkaline environment. The composition dependence activity is discussed in terms of surface density of Mn sites and changes in the effective Mn oxidation state.
\end{abstract}

\section{Introduction}

Oxygen electrocatalysis is one of the key processes limiting the efficiency of energy conversion devices such as fuel cells, electrolysers, and metal-air batteries. ${ }^{[1,2]}$ In particular, the oxygen reduction reaction (ORR) is commonly associated with slow kinetics, requiring high overpotentials, and high catalyst loadings. Current research activities are also focused on the development of non-noble metal electrocatalysis such as transition metal oxides. ${ }^{[3,4]}$ A number of studies have shown that Mnbased transition metal oxides are among the most catalyti-cally active for the ORR in alkaline solutions. ${ }^{[5-8]}$ However, the parameters determining the reactivity of Mn sites in this complex systems remain a subject of discussion.

In the case of perovskites oxides $\left(\mathrm{ABO}_{3}\right)$, the key active site is determined by the B-cation. A multiplicity of parameters have been linked to electrocatalytic activity such as the nature of the A-site, d-orbital occupancy in the B-site, oxidation state, A-site surface segregation, oxygen vacancies, particle size, and morphology. ${ }^{[3,4,9,10]}$ Suntivich et al. proposed that sin-gle occupancy of $e_{g}$ orbital gives the highest ORR activity, ${ }^{[5]}$ which appears to be supported by DFT studies reported by CalleVallejo et al. ${ }^{[9]}$ However, recent studies by Celorrio et al. showed that the B-site orbital occupancy may change under operational conditions, concluding that Mn-sites are uniquely active as they undergo changes in the oxidation state in the region close to the formal ORR potential. ${ }^{[1]}$ This point has also been recognized by other groups. ${ }^{[12,13]}$ The orbital occupancy of Mn can be influenced by the cations occu-pying the A-site, which might lead to tuning the activity of the catalysts. ${ }^{[7]}$ Celorrio et al. also demonstrated that increasing the amount of $\mathrm{Ca}^{2+}$ in $\mathrm{La}_{1-x \mathrm{Cax}} \mathrm{MnO}_{3}$ not only increases the $\mathrm{Mn}$ oxidation state, but also decreases the average activity. ${ }^{[7]}$

In this study, we investigate tellurium (Te)-doped lantha-num manganite as an ORR catalyst for the first time. The rational of Te doping is based on the studies by Yang et al., showing

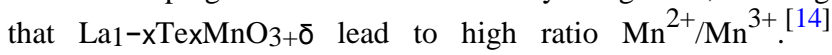

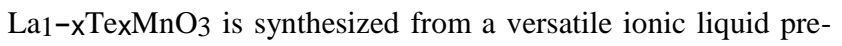
cursor, yielding nanoparticles with size ranging between 40 and $68 \mathrm{~nm}$. At a fixed catalyst loading, the overall performance appears to decrease upon Te doping with respect to $\mathrm{LaMnO}_{3}$. However, normalization of the activity by the number density of electroactive $\mathrm{Mn}$ sites reveals a significant improvement of the Bsite activity upon $10 \%$ Te doping of the A-site.

\section{Experimental}

La1-xTexMnO3 were synthesized employing an ionic liquid precursor based on the methodology described in previous studies. ${ }^{[7,11,15]}$ Firstly, $\sim 9 \mathrm{~mL} 69 \% \mathrm{HNO}_{3}$ was added to a glass vial containing $\mathrm{TeO}_{2}(0.001 \mathrm{~mol})$ and heated to $80{ }^{\circ} \mathrm{C}$ under stirring for $3 \mathrm{~h}$, until the $\mathrm{TeO}_{2}$ had completely dissolved. The colorless solution was diluted to $10 \mathrm{~mL}$ with deionized water to give a $0.1 \mathrm{M}$ solution of $\mathrm{Te}^{4+}$ in aqueous $\mathrm{HNO}_{3}$. Later, $0.029 \mathrm{~g}$ ethylenediaminetetraacetic acid (EDTA) $(0.01 \mathrm{mmol}, 1: 1 \mathrm{molar}$ ratio of metal precursors:EDTA) was added to $1 \mathrm{~mL} 1$-ethyl-3methylimidazolium acetate stirred at $80{ }^{\circ} \mathrm{C}$. Then, $0.1 \mathrm{M}$ aqueous $\mathrm{Mn}\left(\mathrm{NO}_{3}\right)_{2} .4 \mathrm{H}_{2} \mathrm{O}, \mathrm{La}\left(\mathrm{NO}_{3}\right)_{3} .6 \mathrm{H}_{2} \mathrm{O}$ and the $0.1 \mathrm{M} \mathrm{Te}^{4+}$ solution in aqueous $\mathrm{HNO}_{3}$ were added to the ionic liquid in the appropriate stoichiometric ratio. The total vol-ume of aqueous solution added was $1 \mathrm{~mL}$. Solutions were dehy-drated by heating at $80{ }^{\circ} \mathrm{C}$ under stirring for $3 \mathrm{~h}$. Following 
dehydration, the mixture was transferred to an alumina crucible containing $100 \mathrm{mg}$ microcrystalline cellulose. After 10 min of stirring at $\sim 80{ }^{\circ} \mathrm{C}$, a slightly viscous homogeneous gel was obtained. The crucible was transferred to a furnace, and calcined at $850{ }^{\circ} \mathrm{C}$ for $4 \mathrm{~h}$ with a temperature ramp rate of $5{ }^{\circ} \mathrm{C} / \mathrm{min}$. This temperature enabled the formation of phase pure $\mathrm{La}_{1-x \mathrm{Te}} \mathrm{MnO}_{3}$ with $\mathrm{x}$-values below $25 \%$.

Powder $\mathrm{x}$-ray diffraction (XRD) was carried out on a Bruker D8 Advance using $\mathrm{Cu} \mathrm{K}_{\alpha}$ radiation. Experiments were run between $10^{\circ}$ and $80^{\circ}$, using a step size of $0.02^{\circ}$. The XRD pat-terns were refined by the Rietveld method using the FULLPROF program. ${ }^{[16,17]}$ The following parameters were refined: scale factor, background coefficients, zero-point error and positional coordinates. The isotropic thermal factors for all the atoms were fixed to a standard value of $1 \AA^{2}$. No cation deficiency was detected in the case of $\mathrm{LaMnO}_{3}$; thus the occu-pancy factors were fixed to 1 . For $\mathrm{La}_{1-x} \mathrm{Tex}_{\mathrm{XnO}}$, the occu-pancy factors for $\mathrm{La}$ and Te were also refined. Scanning electron microscopy (SEM) was carried out on a JEOL SEM 5600LV scanning electron microscope. Transmission electron microscopy (TEM) was carried out on a JEOL JEM-1400Plus instrument.

X-ray photoelectron spectroscopy (XPS) was carried out at the Bristol NanoESCA Facility equipped with an Argus spectrometer working at a base pressure of $4.0 \times 10^{-11}$ mbar. Core-level photoemission spectra were acquired in grazing inci-dence, i.e. $45^{\circ}$ between the sample surface and the normal of the electron analyzer, with a monochromatic $\mathrm{Al} \mathrm{K}_{\alpha}$ (1486.7 eV), pass energy of $20 \mathrm{eV}$ at room temperature. The binding energy scale was referenced to the carbon $\mathrm{C} 1 \mathrm{~s}$ photoemission line.

Cyclic voltammetry was carried out in argon saturated 0.1 $\mathrm{M} \mathrm{KOH}$ solution using a glassy carbon working electrode, graphite counter electrode, and $\mathrm{Hg} / \mathrm{HgO}$ reference electrode. Linear sweep voltammetry employing a rotating ring-disk elec-trode (RRDE) were carried out in $\mathrm{O}_{2}$-saturated $0.1 \mathrm{M}$ $\mathrm{KOH}$ sol-ution using an ALS rotation controller, and an Ivium compactstat potentiostat. A glassy carbon disk $(0.126$ $\mathrm{cm}^{2}$ ) and a Pt ring were used in all experiments. Working electrodes were prepared via a two-step drop-casting process. First, an aqueous Vulcan/Nafion suspension was dropped onto the sur-face of the electrode, followed by an aqueous suspension of the metal oxide nanoparticles. The sample loading on the elec-trode surface was $50 \mu \mathrm{g}_{\text {vulcan }} / \mathrm{cm}^{2}, 50$ $\mu \mathrm{g}$ nafion $/ \mathrm{cm}^{2}$, and $250 \mu \mathrm{g}_{\text {oxide }} / \mathrm{cm}^{2}$.

\section{Results and discussion}

Figure 1(a) shows the XRD patterns of $\mathrm{LaMnO}_{3}$, $\mathrm{La} 0.90 \mathrm{Te} 0.10 \mathrm{MnO}_{3}$, and $\mathrm{La} 0.77 \mathrm{Te} 0.23 \mathrm{MnO} 3$ as well as the result of the Rietveld refinement employing a rhombohedral lattice with the space group R3-c. $\mathrm{LaMnO}_{3}$ and $\mathrm{La} 0.90 \mathrm{Te} 0.10 \mathrm{MnO}_{3}$ are characterized by high degree of phase purity, whereas La0.77 $\mathrm{Te} 0.23 \mathrm{MnO}_{3}$ exhibit a small peaks associated with an unidentified secondary phase. Ionic liquid precursors incorporating higher Te content yield multiple phases, in agreement with previous studies. ${ }^{[18]}$ Structural parameters were obtained by the Rietveld method and can be found in online Table S1 of the Supporting information. The results show a minimum in the unit-cell volume with increasing Te content (changes below $0.2 \%$ ), while the $\mathrm{Mn}-\mathrm{O}$ bond length increases by approximately $0.1 \%$ in $\mathrm{La}_{0.77} \mathrm{Te}_{0} .23 \mathrm{MnO}_{3}$. These changes in structural parameters appear consistent with previous studies. ${ }^{[19]}$

Figure 1(b) shows a representative SEM image of $\mathrm{LaMnO}_{3}$, illustrating the typical porous microstructure of the synthesized materials, while the TEM image in Fig. 1(c) shows the nano-scale dimensions of the particles (SEM and TEM images of the other oxides can be found in online Figs S1 and S2 of the Supporting Information, respectively). Particle size distribu-tions obtained from measuring at least 80 particles can be found in online Fig. S3, revealing a slight increase in mean par-ticle size with increasing Te content, from $39.9 \pm 11.3 \mathrm{~nm}$ for $\mathrm{LaMnO}_{3}$ to $67.9 \pm 38.3 \mathrm{~nm}$ for La0.77 $\mathrm{Te}_{0.23} \mathrm{MnO}_{3}$ (see online Table S2).

XPS spectra of $\mathrm{LaMnO}_{3}, \mathrm{La} 0.9 \mathrm{Te}_{0} .10 \mathrm{MnO}_{3}, \mathrm{La} 0.77 \mathrm{Te}_{0.23} \mathrm{MnO}_{3}$ are displayed in Fig. 2, showing the La $3 \mathrm{~d}$ (left), Mn $2 p$ (middle) and Te $3 \mathrm{~d}$ (right) regions. The characteristic double peak associ-ated with $\mathrm{La} 3 \mathrm{~d}_{5 / 2}(834.0-834.9 \mathrm{eV})$ and $\mathrm{La} 3 \mathrm{~d}_{3 / 2}(851.0-851.9 \mathrm{eV})$ are observed, with the $\mathrm{La} 3 \mathrm{~d}_{5 / 2}$ binding energy consistent with a $\mathrm{La}^{3+}$ oxidation state. ${ }^{[7,11,20-22]}$ The peak at $874 \mathrm{eV}$, visible for the Tecontaining samples has been assigned to the Te Auger MNN. The Te $3 \mathrm{~d}$ photoemission lines involve the Te $3 \mathrm{~d}_{5 / 2}$ at $576 \mathrm{eV}$ and $\mathrm{Te} 3 \mathrm{~d}_{3 / 2}$ at $586.6 \mathrm{eV}$. These values are consistent with a $\mathrm{Te}^{4+}$ oxidation state. ${ }^{[23,24]}$ Finally, the photoemission line associated with Mn $2 p_{3 / 2}$ peak centered at $642 \mathrm{eV}$ shows an inter-esting trend as function of Te content. This line contains contribu-tion from $\mathrm{Mn}^{2+}(640.9 \mathrm{eV})$ and $\mathrm{Mn}^{3+}(641.9 \mathrm{eV})$ oxidation state. ${ }^{[25]}$ Focusing on this narrow emission range (online Fig. S4), we can see a slight shift of the Mn $2 p_{3 / 2}$ peak towards lower binding energy as the Te content increases. However, given the small differences in binding energies for the two oxidation states, we shall refrain from attempting to estimate $\mathrm{Mn}^{2+} / \mathrm{Mn}^{3+}$ ratio from these data.

Analysis of the relative composition of $\mathrm{La}, \mathrm{Te}$, and $\mathrm{Mn}$, after normalization of the individual photoemission lines by their sensitivity factor and inelastic mean-free path, show a signifi-cant A-site surface enrichment. We obtained an A:B ratio of 62:38 for all three materials, broadly in agreement with data reported for other lanthanides. ${ }^{[7,26]}$ We have also estimated La:Te ratios of 82:18 and 71:29 for $\mathrm{La} 0.90 \mathrm{Te} 0.10 \mathrm{MnO}_{3}$ and $\mathrm{La} 0.77 \mathrm{Te} 0.23 \mathrm{MnO} 3$, respectively. This analysis shows both $\mathrm{La}$ and Te substantially segregate to the surface, with a slight increase in Te content with respect to the bulk values.

Figure 3 shows cyclic voltammograms recorded in an argon-saturated $0.1 \mathrm{M} \mathrm{KOH}$ solution, revealing a two-step reduction from the initial $\mathrm{Mn}$ oxidation state to $\mathrm{Mn}^{2+} \cdot[7,11,12]$ The position of the peak centered at $0.90 \mathrm{~V}$ remains almost unaffected, while the second reduction peak is slightly shifted toward higher potentials upon increasing Te content. The most striking difference is in the current densities, with 


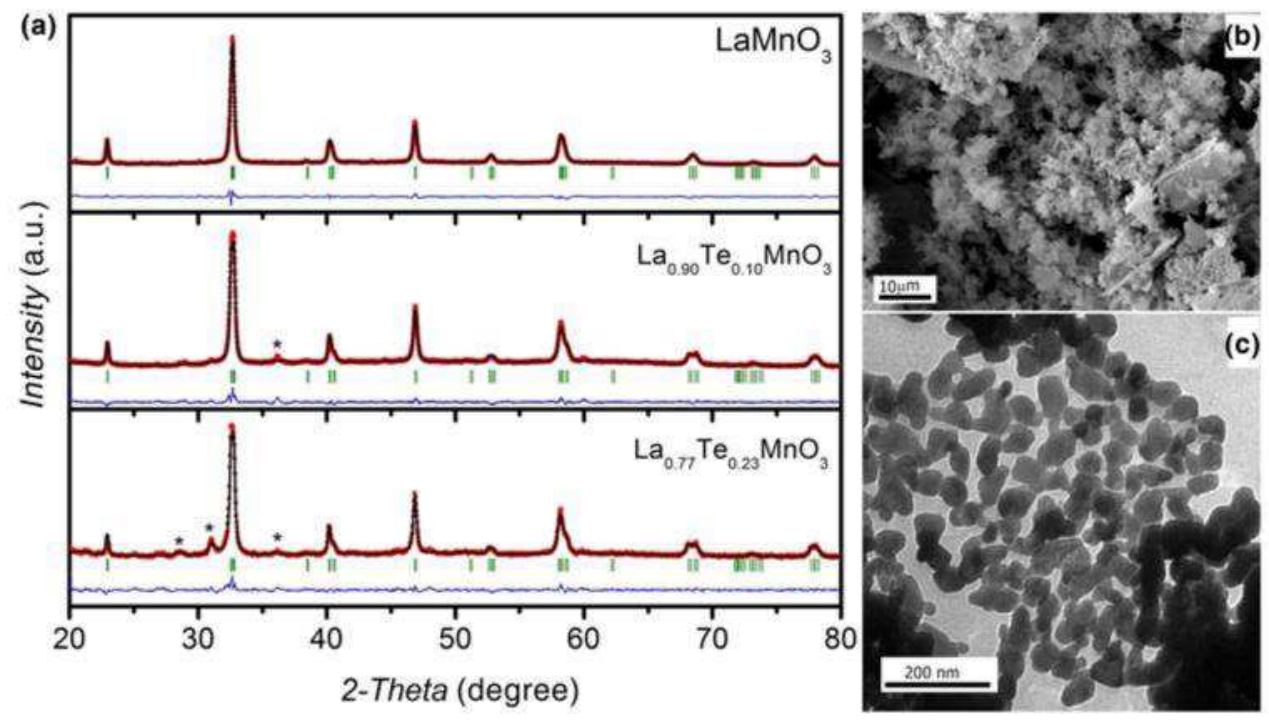

Figure 1. (a) $\mathrm{XRD}$ patterns of $\mathrm{LaMnO}_{3}$, La0.90Te0.10MnO3, and $\mathrm{La} 0.77 \mathrm{Te}_{0} .23 \mathrm{MnO}_{3}$. Red dots correspond to the experimental values while the black thin line corresponds to the Rietveld refinement. The thin blue line shows the difference between experimental and refined patterns. The green bars correspond to the positions of the allowed Bragg reflections for the main phase. (b) SEM and (c) TEM images of as-prepared LaMnO3.

both Te-doped materials showing significantly lower responses than $\mathrm{LaMnO}_{3}$. Considering that the catalyst loading is identical (i.e., $250 \mu \mathrm{g} \times \mathrm{cm}^{-2}$ ), this behavior indicates a decrease in the number density of electrochemically active $\mathrm{Mn}$-sites at the electrode surface. The faradaic charges associated with the anodic and cathodic peaks are very similar, and the responses remain stable in the studied potential range, suggesting that the stability is not significantly compromised within the timescale of these experiments. Integration of the cathodic current peaks in the range of $0.2-1.2 \mathrm{~V}$ enables an estimate of the effective number density of electroactive $\mathrm{Mn}$ sites $\left(\Gamma_{\mathrm{Mn}}\right) .{ }^{[7]}$ In order to calculate $\Gamma_{\mathrm{Mn}}$, two limiting cases can be can be assumed with regard to the initial Mn oxidation state: the oxidation state is determined by the mean oxidation state of the A-site taking $\mathrm{La}^{3+}$ and $\mathrm{Te}^{4+}$ (case 1 ), or fixed Mn oxidation state of +3 independently of the A-site composition (case 2). Case 1 implicitly ignores changes in the oxygen content of the oxide, while case 2 assumes that variations in the mean A-site charge is compensated by changes in oxygen stoichiometry. Our previous studies

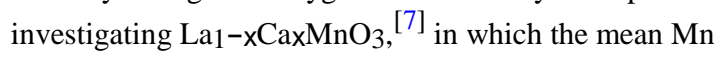
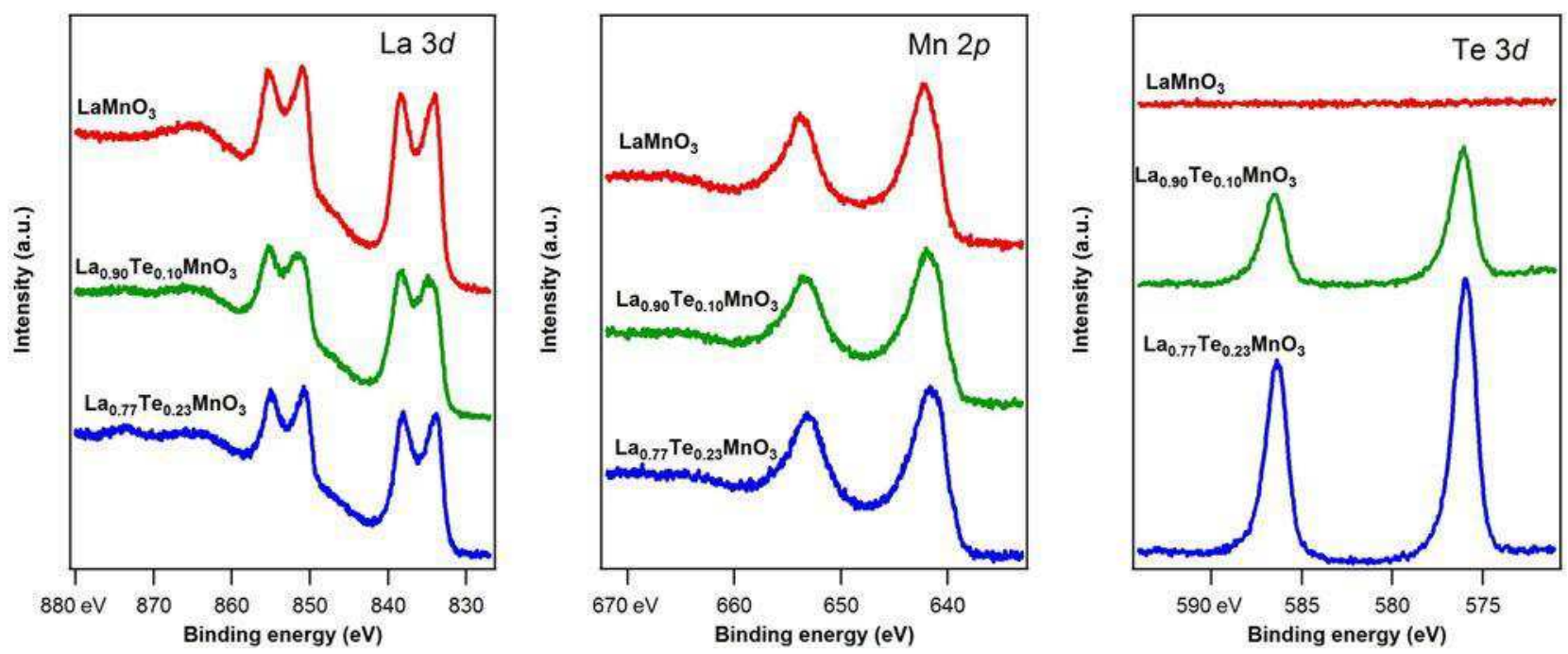

Figure 2. Photoemission spectra of La 3d (left panel), Mn 2p (middle panel) Te 3d (right panel) of the various $\mathrm{La}_{1-x} \mathrm{TexMnO}_{3}$ oxides taken in grazing incidence using a monochromatic $\mathrm{Al} \mathrm{K}_{\alpha} \mathrm{X}$-ray source. 


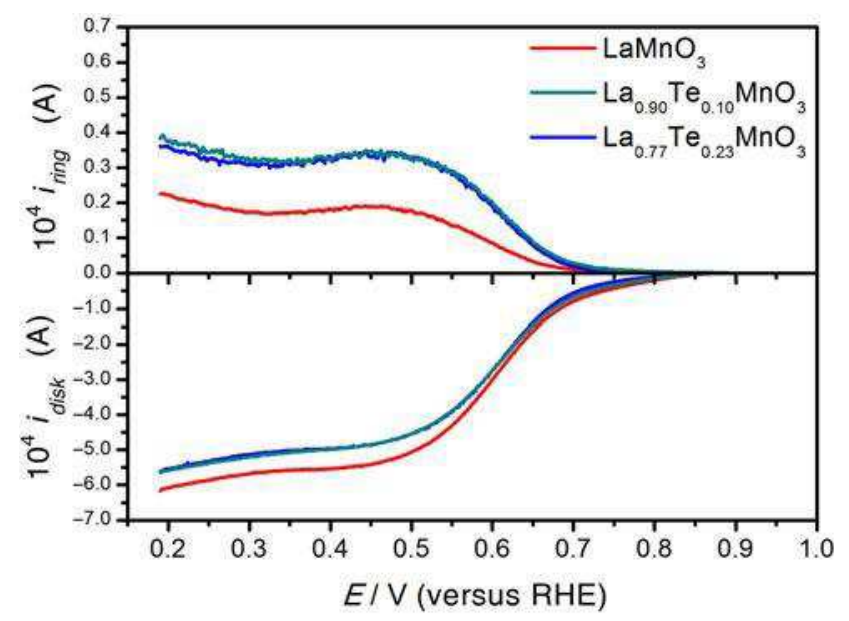

Figure 3. Cyclic voltammograms of $\mathrm{LaMnO}_{3}$, La0.90Te0.10MnO3, and $\mathrm{La}_{0.77} \mathrm{Te}_{0.23} \mathrm{MnO}_{3}$ supported on Vulcan-carbon in Ar-saturated $0.1 \mathrm{M} \mathrm{KOH}$ electrolyte solution at $0.01 \mathrm{~V} / \mathrm{s}$. Electrode loaded with $50 \mu \mathrm{g} / \mathrm{cm}^{2}{ }_{\text {nation, }}^{2} 50 \mathrm{\mu g} /$ $\mathrm{cm}^{2}$ vulcan, and $250 \mu \mathrm{g} / \mathrm{cm}^{2}$ oxide.

oxidation state is directly estimated by XANES, confirms case 1 as a valid approximation. In any case, online Table S3 shows that both limiting cases provide values within the same order of magnitude.

The data in online Table S3 show the $\Gamma_{\mathrm{Mn}}$ is $40 \%-60 \%$ smaller in the Te-doped samples. In view of the similar extent of A-site surface segregation, the smaller $\Gamma_{\mathrm{Mn}}$ values in the case of the Te containing particles is mainly linked to the smaller specific surface area. Although the mean particle size increases with increasing Te content, we see statistically similar $\Gamma_{\mathrm{Mn}}$ in both Te containing oxides. This is due to the fact that size dis-persion also increases in substantial fashion as shown in online Fig. S3. It should also be mentioned that $\Gamma_{\mathrm{Mn}}$ in $\mathrm{LaMnO}_{3}$ prepared at $850{ }^{\circ} \mathrm{C}$ (this report) is lower than those prepared at $700{ }^{\circ} \mathrm{C}$ from the same ionic liquid precursor, ${ }^{[7,11]}$ confirming that calcination temperature is an important parameter to deter-mining A-site segregation.

Figure 4 compares the current measured at the disk (iDISK, bottom panel) and the ring (iRING, top panel) of carbonsupported $\mathrm{LaMnO}_{3}, \mathrm{La} 0.90 \mathrm{Te} 0.10 \mathrm{MnO}_{3}$, and $\mathrm{La} 0.77 \mathrm{Te} 0.23 \mathrm{MnO} 3$ electrodes at $1600 \mathrm{rpm}$ in $\mathrm{O}_{2}$-saturated $0.1 \mathrm{M} \mathrm{KOH}$ solution. The responses obtained from the Vulcan carbon support under the same experimental conditions are shown in online Fig. S5. All of the catalysts show significantly larger currents than the carbon support, while the ORR onset potential is over $100 \mathrm{mV}$ more positive. $\mathrm{LaMnO}_{3}$ exhibit larger cathodic current at the disk, with smaller ring current across the potential range. Current-potential curves recorded for $\mathrm{La} 0.77 \mathrm{Te} 0.23 \mathrm{MnO}_{3}$ particles at various angular rotation rates are displayed in online Fig. S6. Both Tedoped oxides exhibit rather similar current-potential characteristics.

Figure 5 illustrates the dependence of iDISK with the inverse of the angular rotation rate in the case of $\mathrm{LaMnO}_{3}$ [Fig. 5(a)]

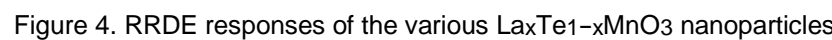
supported at Vulcan layer at $1600 \mathrm{rpm}$ in O2-saturated $0.1 \mathrm{M} \mathrm{KOH}$ at $0.010 \mathrm{~V} / \mathrm{s}$. The Pt ring was held at a constant potential of $1.10 \mathrm{~V}$. The oxide content in each electrode was $250 \mu \mathrm{g} / \mathrm{cm}^{2}$.

and $\mathrm{La}_{0.77} \mathrm{Te}_{0.23} \mathrm{MnO}_{3}$ [Fig. 5(b)], which follows the Koutecky-Levich relationship:

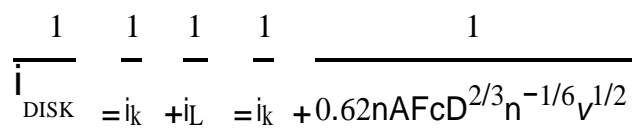

where $\mathrm{n}$ is the number of transferred electrons, $\mathrm{A}$ is the disk geometric area, $\mathrm{F}$ is the Faraday constant, $\mathrm{C}$ is the bulk oxygen concentration $\left(1.2 \times 10^{-6} \mathrm{~mol} / \mathrm{cm}^{3}\right),{ }^{[27]} \mathrm{D}$ is the oxygen diffusion coefficient $\left(1.9 \times 10^{-5} \mathrm{~cm}^{2} / \mathrm{s}\right), \mathrm{v}$ is the kinematic viscosity $\left(0.01 \mathrm{~cm}^{2} / \mathrm{s}\right)$, and $\omega$ is the angular rotation of the electrode. $i_{\mathrm{k}}$ and $i_{\mathrm{L}}$ are the kinetically and mass-transport limiting currents, respectively. It can be observed that $\mathrm{LaMnO}_{3}$ [Fig. 5(a)] shows a linear dependence, with a slope consistent with $n=4 .{ }^{[7,11]}$ In the case of $\mathrm{La}_{0.77 \mathrm{Te}} 0.23 \mathrm{MnO}_{3}$ [Fig. 5(b)], only a slight deviation from $n=4$ is observed at high rotation rate.

The $\mathrm{HO}_{2}^{-}$yield (two-electron process) as a function of potential was calculated from the ring and the disk current val-ues at $1600 \mathrm{rpm}$ [online Fig. S7(a)]. The Vulcan support shows almost $100 \% \mathrm{HO}^{-} 2$ yield between 0.2 and $0.6 \mathrm{~V}$, while $\mathrm{LaMnO}_{3}$ and both Te-doped catalysts exhibit $<30 \%$. The pathway selec-tivity can also be described in terms of the effective number of electrons shown in online Fig. S7(b). The Vulcan support yields values close to 2 , increasing to values above 3.4 upon introduction of the oxide catalysts.

These findings suggest that $\mathrm{LaMnO}_{3}$ exhibits better performance than the Te-doped under the specific catalyst formulation used, i.e., at equivalent mass loading. However, it should also be considered that mean particle sizes and size dispersion are composition dependent, which have an effect on the overall catalysts performance. Furthermore, XPS data shows an increase in the A-site segregation in the presence of Te, although the surface composition remains dominated by $\mathrm{La}^{3+}$. 

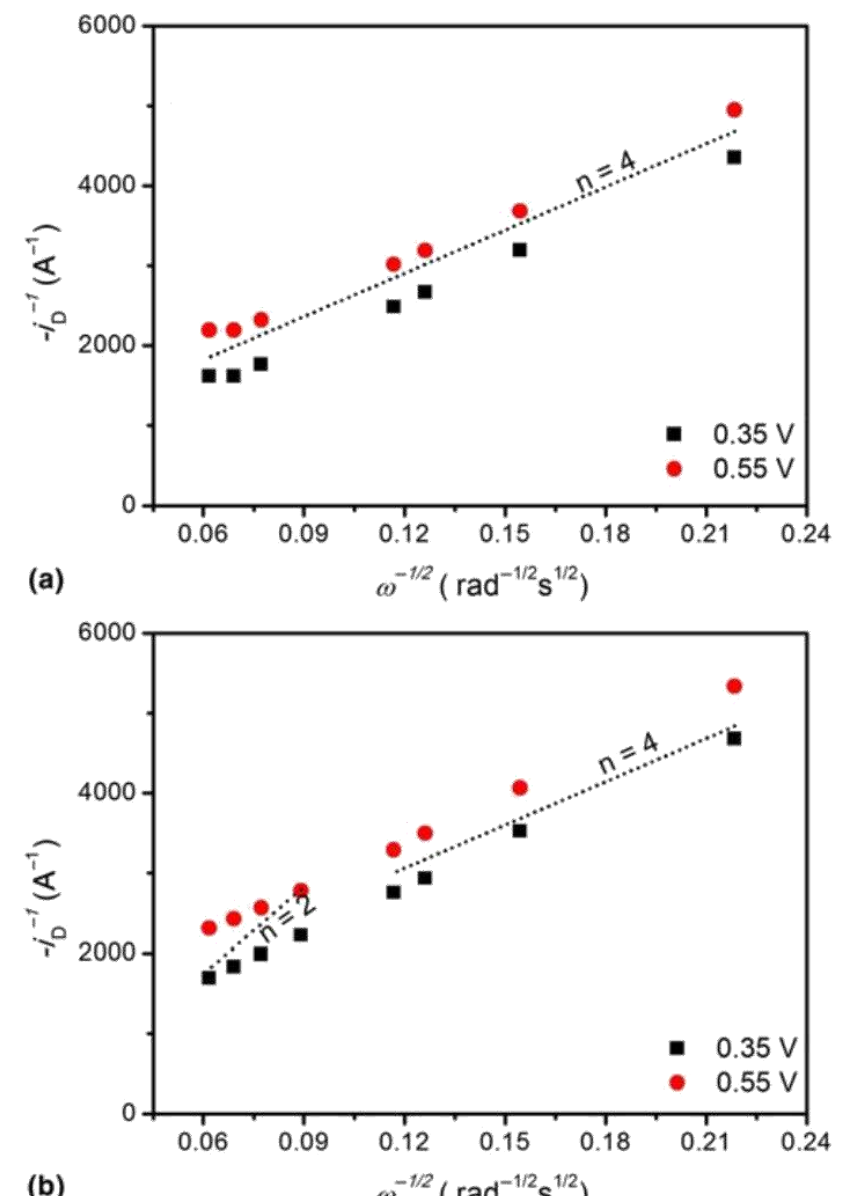

(b)

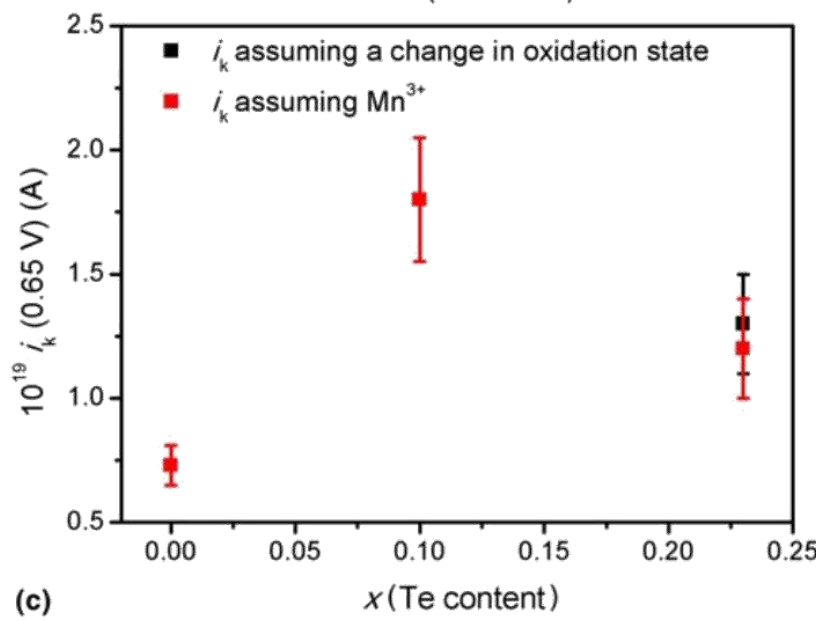

Figure 5. Koutecky-Levich plots of (a) $\mathrm{LaMnO}_{3}$ and (b) La0.77 $\mathrm{Te}_{0.23 \mathrm{MnO}_{3}}$ electrodes in $\mathrm{O}_{2}$-saturated $0.1 \mathrm{M} \mathrm{KOH}$ at 0.55 and $0.35 \mathrm{~V}$. Dotted lines represent the limiting slopes for the two and four-electron processes. (c) Kinetically limited current at $0.65 \mathrm{~V}$ normalized by the effective number of electroactive $\mathrm{Mn}$ atoms (îk).

In order to account for these parameters, the kinetically limiting

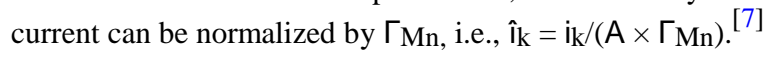

Figure 5(c) illustrates the variation of $\hat{i}_{\mathrm{k}}$ at $0.65 \mathrm{~V}$ as a function of the Te content, obtained from at least three different samples from various synthesis batches. The contribution of the carbon support to the overall current at this potential is neg-ligible in comparison with the oxide loaded catalysts (see online Fig. S4). Two sets of data are plotted based on the two limiting cases used for calculating $\Gamma_{\mathrm{Mn}}$. It is interesting to see the performance of electrochemically active surface Mn sites increases on average in the presence of Te. Surface Mn sites in materials containing $10 \%$ Te appears twice more active than surface Mn-sites in $\mathrm{LaMnO}_{3}$. The performance seems to slightly degrade for larger Te content.

We rationalize this early trend in terms of changes in the electron density at $\mathrm{Mn}$ sites. Incorporating $10 \% \mathrm{Te}$ in the Asite, most probably in a 4+ oxidation state, effectively increases the electron density at the B-site, leading to an enhancement in the catalytic activity for ORR. Indeed, the slight shift in the binding energy of the Mn 2p3/2 peak suggests a decrease in the oxidation state on Mn sites in the presence of Te (Figs 2 and S4). A similar correlation have

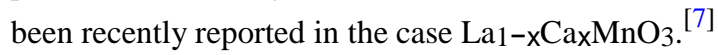

In conclusion, these studies reveal an increase in the mean activity of surface $\mathrm{Mn}$ sites upon $\mathrm{Te}^{4+}$ doping in the A-site. The most active surface $\mathrm{Mn}$ sites were obtained upon $10 \%$ replacement of $\mathrm{La}^{3+}$ by $\mathrm{Te}^{4+}$, leading to an increase of the elec-tron density at the Mn site without compromising the coordina-tion structure. To confirm this hypothesis, a number of parameters should be systematically explored such as the effect of low oxidation state cations with different sizes as well as the activity of different $\mathrm{LaMnO}_{3}$ phases. In any case, our studies demonstrate the need of establishing universal descriptors, such as $\hat{\imath}_{\mathrm{k}}$, which uncovers the mean activity of surface Mn sites, independently of the particle size, dispersion quality, and complex phenomena such as A-site segregation.

\section{Acknowledgment}

The authors acknowledge Dr. Devendra Tiwari and Gael Gobaille-Shaw for the fruitful discussions. V. C. and D. J. F. are thankful to the UK Catalysis Hub (EPSRC grants EP/ K014706/1 and EP/K014714/1) for resources and support. L. J. M. and D. J. F. are also grateful to the EPSRC Centre for Doctoral Training in Catalysis for the financial sup-port. SEM/EDX and TEM studies were carried out in the Chemistry Imaging Facility at the University of Bristol with equipment partly funded by EPSRC (EP/K035746/1 and EP/ M028216/1). Authors acknowledge access to the Bristol NanoESCA Facility under EPSRC Strategic Equipment Grant EP/M000605/1. D. J. F. also acknowledges the University Research Fellowship (2015-2016) provided by the Institute of Advanced Studies of the University of Bristol. 


\section{References}

1. F. Cheng and J. Chen: Metal-air batteries: from oxygen reduction electrochemistry to cathode catalysts. Chem. Soc. Rev. 41, 2172 (2012).

2. D.U. Lee, P. Xu, Z.P. Cano, A.G. Kashkooli, M.G. Park, and Z. Chen: Recent progress and perspectives on bi-functional oxygen electrocata-lysts for advanced rechargeable metal-air batteries. J. Mater. Chem. A 4, 7107 (2016).

3. L. Li, X. Feng, S. Chen, F. Shi, K. Xiong, W. Ding, X. Qi, J. Hu, Z. Wei, L-J. Wan, and M. Xia: Insight into the effect of oxygen vacancy concentration on the catalytic performance of MnO2. ACS Catal. 5, 4825 (2015).

4. W.G. Hardin, J.T. Mefford, D.A. Slanac, B.B. Patel, X. Wang, S. Dai, X. Zhao, R.S. Ruoff, K.P. Johnston, and K.J. Stevenson: Tuning the electrocatalytic activity of perovskites through active site variation and support interactions. Chem. Mater. 26, 3368 (2014).

5. J. Suntivich, H.A. Gasteiger, N. Yabuuchi, H. Nakanishi, J. B. Goodenough, and Y. Shao-Horn: Design principles for oxygen-reduction activity on perovskite oxide catalysts for fuel cells and metal- air batteries. Nat. Chem. 3, 546 (2011).

6. K.A. Stoerzinger, M. Risch, B. Han, and Y. Shao-Horn: Recent insights into manganese oxides in catalyzing oxygen reduction kinetics. ACS Catal. 5, 6021 (2015).

7. V. Celorrio, L. Calvillo, E. Dann, G. Granozzi, A. Aguadero, D. Kramer, A.

E. Russell, and D.J. Fermin: Oxygen reduction reaction at $\mathrm{La}_{x} \mathrm{Ca}_{1-\mathrm{x}} \mathrm{MnO}_{3}$ nanostructures: interplay between A-site segregation and B-site valency. Catal. Sci. Tech. 6, 7231 (2016).

8. X. Ge, A. Sumboja, D. Wuu, T. An, B. Li, F.W.T. Goh, T.S.A. Hor, Y. Zong, and Z. Liu: Oxygen reduction in alkaline media: from mechanisms to recent advances of catalysts. ACS Catal. 5, 4643 (2015).

9. F. Calle-Vallejo, N.G. Inoglu, H-Y. Su, J.I. Martinez, I.C. Man, M.T. M. Koper, J.R. Kitchin, and J. Rossmeisl: Number of outer electrons as descriptor for adsorption processes on transition metals and their oxides. Chem. Sci. 4, 1245 (2013).

10. W. Lee, J.W. Han, Y. Chen, Z. Cai, and B. Yildiz: Cation size mismatch and charge interactions drive dopant segregation at the surfaces of manganite perovskites. J. Am. Chem. Soc. 135, 7909 (2013).

11. V. Celorrio, E. Dann, L. Calvillo, D.J. Morgan, S.R. Hall, and D.J. Fermin: Oxygen reduction at carbon-supported lanthanides: the role of the B-site. ChemElectroChem 3, 283 (2016).

12. A.S. Ryabova, F.S. Napolskiy, T. Poux, S.Y. Istomin, A. Bonnefont, D.M. Antipin, A.Y. Baranchikov, E.E. Levin, A.M. Abakumov, G. Kéranguéven, E.V. Antipov, G.A. Tsirlina, and E.R. Savinova: Rationalizing the influence of the $\mathrm{Mn}(\mathrm{IV}) / \mathrm{Mn}$ (III) red-ox transition on the electrocatalytic activity of manganese oxides in the oxygen reduction reaction. Electrochim. Acta 187, 161 (2016).

13. W.T. Hong, M. Risch, K.A. Stoerzinger, A. Grimaud, J. Suntivich, and Y. Shao-Horn: Toward the rational design of non-precious transition metal oxides for oxygen electrocatalysis. Energy Environ. Sci. 8, 1404 (2015).

14.J. Yang, W.H. Song, Y.Q. Ma, R.L. Zhang, and Y.P. Sun: Determination of oxygen stoichiometry in the mixed-valent manganites. J. Magn. Magn. Mater. 285, 417 (2005).

15.D.C. Green, S. Glatzel, A.M. Collins, A.J. Patil, and S.R. Hall: A new gene-ral synthetic strategy for phase-pure complex functional materials. Adv. Mater. 24, 5767 (2012).

16.J. Rodríguez-Carvajal: Recent advances in magnetic structure determina-tion by neutron powder diffraction. Phys. B: Condens Matter 192, 55 (1993).

17.H. Rietveld: A profile refinement method for nuclear and magnetic struc-tures. J. Appl. Crystallogr. 2, 65 (1969).

18.J. Yang, W.H. Song, Y.Q. Ma, R.L. Zhang, B.C. Zhao, Z.G. Sheng, G.H. Zheng, J.M. Dai, and Y.P. Sun: Insulator-metal transition and the magnetic phase diagram of La1-xTexMnO3 $(0.1 \leq x \leq 0.6)$. Mater. Chem. Phys. 94, 62 (2005).

19. G.H. Zheng, Y.P. Sun, X.B. Zhu, and W.H. Song: Transport, magnetic, internal friction, and Young's modulus in the $Y$-doped manganites La0.9-xYxTe0.1MnO3. J. Solid State Chem. 179, 1394 (2006).

20.M.F. Sunding, K. Hadidi, S. Diplas, O.M. Løvvik, T.E. Norby, and A. E. Gunnæs: XPS characterisation of in situ treated lanthanum oxide and hydroxide using tailored charge referencing and peak fitting procedures. J. Electron. Spectrosc. Relat. Phenom. 184, 399 (2011).

21. M.C. Álvarez-Galván, V.A. de la Peña O’Shea, G. Arzamendi, B. Pawelec, L. M. Gandía, and J.L.G. Fierro: Methyl ethyl ketone combustion over La-transition metal ( $\mathrm{Cr}, \mathrm{Co}, \mathrm{Ni}, \mathrm{Mn})$ perovskites. Appl. Catal. B 92, 445 (2009).

22. K. Bolwin, W. Schnurnberger, and G. Schiller: Influence of valence band states on the core hole screening in lanthanide perovskite compounds. Z. Phys. B 72, 203 (1988).

23. A.B. Christie, I. Sutherland, and J.M. Walls: Studies of the composition, ion-induced reduction and preferential sputtering of anodic oxide films on Hg0.8Cd0.2Te by XPS. Surf. Sci. 135, 225 (1983).

24. R.F.C. Farrow, P.N.J. Dennis, H.E. Bishop, N.R. Smart, and J.T. M. Wotherspoon: The composition of anodic oxide films on Hg0.8Cd0.2Te. Thin Solid Films 88, 87 (1982).

25. V. Di Castro and G. Polzonetti: XPS study of MnO oxidation. J. Electron. Spectrosc. Relat. Phenom. 48, 117 (1989).

26. J. Druce, H. Tellez, M. Burriel, M.D. Sharp, L.J. Fawcett, S.N. Cook, D. S. McPhail, T. Ishihara, H.H. Brongersma, and J.A. Kilner: Surface termi-nation and subsurface restructuring of perovskite-based solid oxide elec-trode materials. Energy Environ. Sci. 7, 3593 (2014).

27.A.J. Bard: Chapter 9: Methods involving forced convectionhydrodynamic methods. In Electrochemical Methods: Fundamentals and Applications, edited by A.J. Bard and L.R. Faulkner (Wiley, New York, 1980), pp. 331-367. 